\title{
Preliminary Investigations of Joining Technologies for Attaching Refractory Metals to Ni-Based Superalloys
}

\author{
Jerry E. Gould, ${ }^{1}$ Frank J. Ritzert, ${ }^{2}$ and William S. Loewenthal ${ }^{3}$ \\ ${ }^{1 a}$ Edison Welding Institute, 1250 Arthur E. Adams Drive, Columbus, OH 43221 \\ ${ }^{2}$ NASA Glenn Research Center, 21000 Brookpark Road, Mail Stop 49-1, Cleveland, OH 44135 \\ ${ }^{3}$ Ohio Aerospace Institute, 21000 Brookpark Road, Mail Stop 49-1, Cleveland, OH 44135 \\ ${ }^{1 a}$ 614-688-5121,614-688-5001,jerry_gould@ewi.org
}

\begin{abstract}
In this study, a range of joining technologies has been investigated for creating attachments between refractory metal and Ni-based superalloys. Refractory materials of interest include Mo-47\%Re, T-111, and Ta- $10 \% \mathrm{~W}$. The Ni-based superalloys include Hastelloy X and MarM 247. During joining with conventional processes, these materials have potential for a range of solidification and intermetallic formation-related defects. For this study, three non-conventional joining technologies were evaluated. These included inertia welding, electro-spark deposition (ESD) welding, and magnetic pulse welding (MPW). The developed inertia welding practice closely paralleled that typically used for the refractory metals alloys. Metallographic investigations showed that forging during inertia welding occurred predominantly on the nickel base alloy side. It was also noted that at least some degree of forging on the refractory metal side of the joint was necessary to achieve consistent bonding. Both refractory metals were readily weldable to the Hastelloy X material. When bonding to the MarM 247, results were inconsistent. This was related to the higher forging temperatures of the MarM 247, and subsequent reduced deformation on that material during welding. ESD trials using a Hastelloy $X$ filler were successful for all material combinations. ESD places down very thin $(5-$ to $10-\mu \mathrm{m})$ layers per pass, and interactions between the substrates and the fill were limited (at most) to that layer. For the refractory metals, the fill only appeared to wet the surface, with minimal dilution effects. Microstructures of the deposits showed high weld metal integrity with maximum porosity on the order of a few percent. Some limited success was also obtained with MPW. In these trials, only the T-111 tubes were used. Joints were possible for the T-111 tube to the Hastelloy X bar stock, but the stiffness of the tube (resisting collapse) necessitated the use of very high power levels. These power levels resulted in damage to the equipment (concentrator) during welding. It is of note that the joint made showed the typical wavy bond microstructure associated with magnetic pulse/explosion bond joints. Joints were not possible between the T-111 tube and the MarM 247 bar stock. In this case, the MarM 247 shattered before sufficient impact forces could be developed for bonding.
\end{abstract}

Keywords: Dissimilar materials joining, refractory metals, superalloys, inertia welding, electro-spark deposition, magnetic pulse welding

PACS: 81.05.Je, 81.20Uj

\section{INTRODUCTION}

Project Prometheus is an aggressive effort to develop nuclear/electric propulsion for deep-space exploration. The basic concepts under consideration include a compact fission reactor coupled with a Brayton cycle turbine. The turbine would then drive on-board generators, providing electrical power for both propulsion as well as other onboard systems. System efficiency is largely controlled by heat transfer. In space applications, this is exclusively radiant heat transfer. Since radiant heat transfer rates scale as $\mathrm{T}^{4}$ (temperature to the fourth power), achievable power levels increase dramatically with peak operating temperatures. Current designs include reactor outlet working fluid temperatures as high as $850^{\circ} \mathrm{C}$. Refractory metals could be applied here. The Brayton cycle turbine, however, uses working fluid systems largely manufactured from Ni-based superalloys. Assembly of the system then requires joining technologies capable of attaching these disparate materials. 
Refractory metals intended for this application include an Mo-Re alloy and Ta-W alloys. Candidate Ni-based superalloys include both wrought and cast variants. Metallurgically, bonding of either Mo- or Ta-based systems to Ni-based systems is problematic. In both cases, there are disparities in melting points, low melting eutectics, and a range of intermetallic compounds. The presence of eutectics is problematic in that this can lead to solidification cracking in the fusion zone, as well as liquation cracking in the heat-affected zone (HAZ). Brittle, intermetallic formation can lead to poor mechanical performance in the weld area. These concerns largely rule out conventional fusion welding processes for these applications. In this study, three technologies have been considered for accomplishing these dissimilar materials joints. These include inertia, electro-spark deposition (ESD), and magnetic pulse welding (MPW).

Inertia welding is a well-defined solid-state joining technology (R. L. O'Brien, ed.; 1991), widely used for dissimilar materials joining. Inertia welding is a variant of friction welding that uses relative rotation velocities of the components to generate frictional heat, thereby providing the temperature excursions necessary for forge bonding. This process is considered a candidate given that no melting occurs during joining. Provided that the weld and upset pressures are sufficient, welding can occur below temperatures where eutectics form, allowing joining purely through solid-state mechanisms. In addition, if short thermal cycles (high forces, low inertias, low spindle speeds) are incorporated, intermetallic reactions can also be suppressed. ESD has been widely studied as a coating and repair process in the aerospace industry (Sheldon and Johnson, 1985; Johnson and Sheldon, 1986; Johnson, 1988; Galinov and Luban, 1996; Wand et al., 1997; Li, 1997). ESD uses a capacitor power supply to provide a series of rapid, high current pulses. Typical current pulses are on the order of $500 \mathrm{~A}$, have a rise time of roughly $15 \mu \mathrm{s}$, and are delivered at rates up to $1000 \mathrm{~Hz}$. ESD uses a torch with a rotating electrode that is fabricated from the deposition material of interest. The individual current pulses melt small volumes of material from the electrode and as this material strikes the substrate surface, it results in individual depositions on the order of $1-\mu \mathrm{m}$ thick. This causes rapid cooling and suppresses the segregation and phase transformation reactions described above.

The final process of interest is MPW. The principles of MPW have been widely discussed (Powers, 1967; Khrenov and Chudakov, 1968; Masumoto, Tamaki, and Kojima 1985; Hokari et al., 1998; Shriban, 2000) and are also widely used for dissimilar materials joining (Masumoto, Tamaki, and Kojima, 1985; Hokari et al., 1998; Efimenko et al., 1985; Seregeeva, Chudakov, and Gordon, 1989). MPW essentially uses Lorenz forces to accelerate a tubular component (termed the "flier") against a static component (termed the "target"). These forces can be developed in sufficient magnitude to achieve conditions necessary for explosion type bonding (Shriban, 2000). Lorenz forces are created by coupling a coil (surrounding the flier) with a large capacitor bank. Discharge of these capacitors into the coil results in a current surge that can reach 1,000,000 A, over a total pulse width that can range from 15 to $50 \mu \mathrm{s}$. During discharge, the current from the coil induces a reaction current in the flier. Repulsion of these two currents leads to the Lorenz forces that create the subsequent weld. Microstructures of the resulting bonds have also been widely studied (Efimenko et al., 1985; Seregeeva, Chudakov, and Gordon 1989; Markashova et al., 1991; Stern and Aizenshtein, 2002). Best bonding is generally equated with wavy interfaces, similar to those seen in explosion welding. The bonding itself appears to be a mixture of solid-state and local fusion. The process offers both solidstate and rapid solidification bonding mechanisms, along with rapid cooling rates, and is considered a candidate technology for the materials of interest here.

\section{EXPERIMENTAL PROCEDURES}

Six materials were supplied by NASA Glenn Research Center for these trials. These materials included two variants of refractory alloys and three variants of Ni-based superalloys. Refractory alloys included Mo- $47 \% \mathrm{Re}, \mathrm{T}-111$, and Ta-10\%W. Ni-based superalloys included Hastelloy X, a conventionally cast MarM 247, and a fine cast MarM 247. The Mo- $47 \%$ Re, $\mathrm{T}-111$, and Ta- $10 \% \mathrm{~W}$ were supplied in three forms. These included 13 -mm-diameter bar for the inertia welding trials, 13 -mm-wide $\times 0.5$-mm-thick sheet for the ESD trials, and 13-mm-diameter OD, 0.9-mm-wall tubing for the MPW trials. The Hastelloy X and both variations of MarM 247 were supplied in two forms. These included 13-mm-diameter bar for the inertia and MPW trials, and 13-mm-wide $\times 0.5$-mm-thick sheet for the ESD trials. The MarM 247 sheet supplied for the ESD trials were wire EDM cut from the cast 13-mm-diameter bar into $1 / 2$ tensile specimens by NASA Glenn Research Center.

Inertia welding trials were done on an MTI 120B system. The unit is capable of spindle speeds up to 10,000 rpm and forge forces up to $67 \mathrm{kN}$. Maximum system inertia for this unit is $19 \mathrm{wk}^{2}$. ESD trials were done with a 
dedicated ASAP power supply. This unit has available capacitances up to $50 \mu \mathrm{F}$, chargeable up to $400 \mathrm{~V}$. The unit is capable of sparking rates up to $1000 \mathrm{~Hz}$. Deposition is done with an ASAP supplied torch. The torch uses a rotating electrode of nominally $1.6-\mathrm{mm}$ in diameter. The torch had a maximum electrode rotation speed of 1500 $\mathrm{rpm}$. Since oxidation during deposition was a major concern, all deposition trials were done in a hard glove box. In this glove box, the dewpoint could be maintained below $-70^{\circ} \mathrm{C}$ and 1-ppm oxygen. The power supply, torch, and any necessary tooling were placed in the chamber prior to conducting the deposition trials. The ESD setup included $\mathrm{a} \mathrm{Cu}$ fixture with two restraining straps. In addition, Hastelloy backing plates and run-off tabs were used to maintain both quality and geometry of the joint. MPW was done with a Magniform 90-kJ power supply. This unit incorporates up to $1800 \mu \mathrm{F}$ of capacitance, and can be charged at voltages up to $10 \mathrm{kV}$. The development of magnetic pulses for bonding was done through a coil/concentrator arrangement. The main coil is made of $\mathrm{Al}$, and coupled with the system capacitors through some special low-impedance coaxial cables. The coil itself has an interior diameter of $180 \mathrm{~mm}$. This coil was coupled to the flier through a field concentrator which is a ring of $\mathrm{Cu}$ that is tapered from the width of the main coil to that of the active area on the flier. In addition, the concentrator itself acts as a one-turn transformer. Currents induced in the concentrator from the main coil flow along the outside surface, along the gap, and in the reverse direction at the ID of the concentrator. In this way, a single coil can be adapted to a specific part geometry.

All samples for metallographic examination were sectioned and prepared using standard techniques. Etching of the samples was done in two stages given the presence of two separate metals on either side of the joint. The Ni-based superalloy half of the joint was etched with a $40 \% \mathrm{HCL}, 30 \% \mathrm{HNO}_{3}, 10 \%$ glycerol, $20 \%$ acetic acid solution. This solution allowed clear resolution of the retained solidification structure in these materials. The refractory alloy half of the joint was etched in a $20 \% \mathrm{HF}, 10 \% \mathrm{HNO}_{3}, 15 \% \mathrm{H}_{2} \mathrm{SO}_{4}$, balance $\mathrm{H}_{2} \mathrm{O}$ solution which was effective in decorating grain and structural boundaries in these materials. All resulting samples were examined on a Nikon metallography and crude mechanical testing was used to estimate the quality of samples made during the inertia welding trials. Samples were tested in the as-welded condition; that is, without removal of the retained weld flash. Testing was done in a Southwark $90-\mathrm{kN}$ hydraulic tensile testing machine.

\section{RESULTS}

Inertia welding evaluations were done on six combinations of materials. These included the Mo- $47 \%$ Re and Ta10\%W materials welded to Hastelloy X, fine-grained MarM 247, and coarse-grained MarM 247, respectively. The refractory base materials both showed a microstructure characterized by relatively large equiaxed grains (nominally 100 to $300 \mu \mathrm{m}$ in diameter) and smaller second-phase particles (5- to $10-\mu \mathrm{m}$ ). The Hastelloy X also showed an equiaxed (30- to 50- $\mu \mathrm{m}$ diameter) morphology. The residual solidification structure was evident in both the coarseand fine-grained MarM 247 materials. Grain sizes for the two products ranged from roughly $50 \mu \mathrm{m}$ (fine-grained material) to several millimeters (coarse-grained material).

The welding trials themselves were conducted in an iterative manner with all material combinations welded at nearly identical conditions. Further, these conditions closely matched the recommended practice for the refractory metal alloys to themselves (MTI Manual). This practice included short stick-outs for both workpieces from the chucks, low inertia $\left(1.8-\mathrm{wk}^{2}\right)$, a high initial spindle speed $(8700-\mathrm{rpm})$, a low scrub force $(3.6-\mathrm{kN})$, high upset force $(107-\mathrm{kN})$, and a short duration (to 6100-rpm) to initiate that upset force. Joint preparation varied for the different material combinations. Joint strengths between the refractory metals and the Hastelloy X material were reasonably consistent, ranging from roughly 36 to $50 \mathrm{kN}$. When using the MarM 247 material, however, strengths ranged from as low as $9 \mathrm{kN}$ to up to $36 \mathrm{kN}$. It was noted that welds made with the coarse-grained variants of the MarM 247 were, on average, twice as strong as when the fin-grained variant was used.

A characteristic macrostructure for an inertia weld made between Mo- $47 \%$ Re and the Hastelloy X material is shown in Figure 1. It is clear from the macrograph that there is highly localized forging on the Hastelloy X side of the joint. This appears to result from both preferential softening in that material as well as the constraint offered by the short stick-out used. There is also some evidence of cracking in the extruded flash. Bonding appears to extend across the contacting area of the two materials. Some deformation of the Mo- $47 \%$ Re exists but this is much more diffuse than that seen in the Hastelloy X. Some detail of the bond line microstructure is presented in Figure 2. This figure shows that the majority of the high strain deformation associated with the process occurs on the Hastelloy X side of the joint. This is observed as a featureless band along the bondline, bounded by the refractory metal on one 
side, and obvious deformed grains in the Hastelloy $\mathrm{X}$ on the other. Of interest is the deformation zone in the Hastelloy X adjacent to this featureless band. Here, there is both elongation of the Hastelloy X grain structure as well as extensive twinning. Similar results were seen welding the Ta- $10 \% \mathrm{~W}$ material to the Hastelloy X.

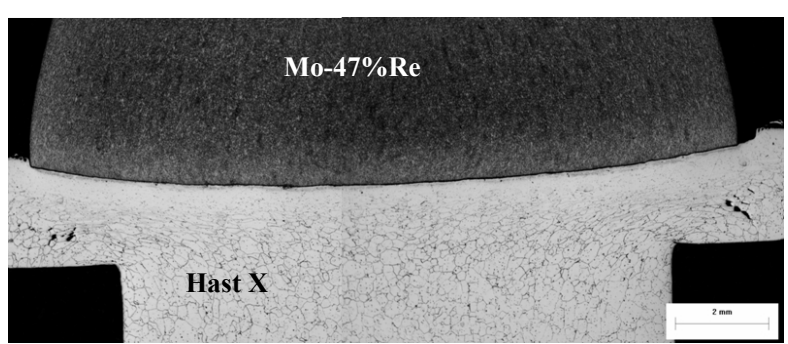

FIGURE 1. Macrostructure from a Mo-47\%Re to Hastelloy X Weld made at Best-Practice Conditions in this Study.

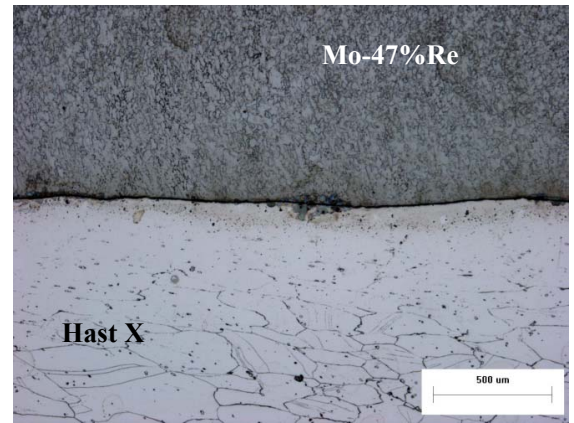

FIGURE 2. Details of the Bondline from a Mo-47\%Re to Hastelloy X Weld made at Best-Practice Conditions in this Study.

A typical micrograph for an inertia weld between the Mo-47\%Re to the coarse-grained MarM 247 is shown in Figure 3. The macrograph shows some limited surface deformation on the coarse-grained MarM 247. Also, there is a more diffuse deformation on the Mo- $47 \%$ Re side, with evidence of longitudinal cracking extending from the bond line. The cracks appear to result from a combination of circumferential strains, combined with localized melting at the bond line. Some detail of the center section of this bond (between the cracks) is presented in Figure 4. In this micrograph, the undeformed residual solidification structure of the coarse-grained MarM 247, as well as a featureless deformation zone in the Mo- $47 \%$ Re are clear. Of interest, however, is a thin region at the bondline, roughly 50- $\mu \mathrm{m}$ wide, apparently matching the undeformed coarse-grained MarM 247 structure to the Mo-47\%Re. This region appears both heavily worked and to contain elements of both base materials. Such material was also seen to extrude into the longitudinal cracks visible in Figure 3.

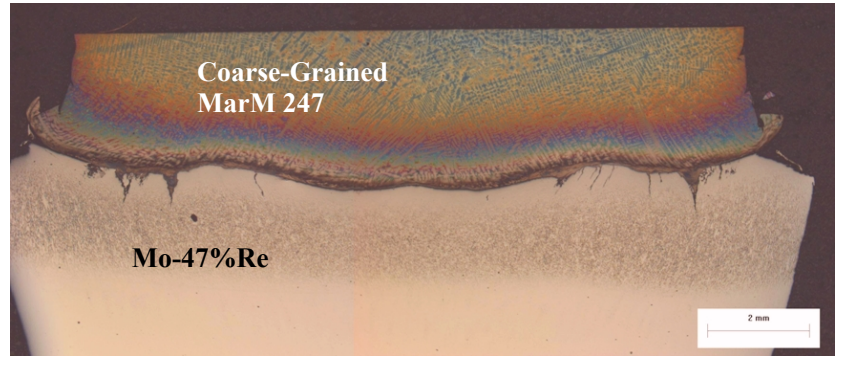

FIGURE 3. Macrostructure from a Mo-47\%Re to a Coarse-Grained MarM 247 Weld made at Best-Practice Conditions in this Study.

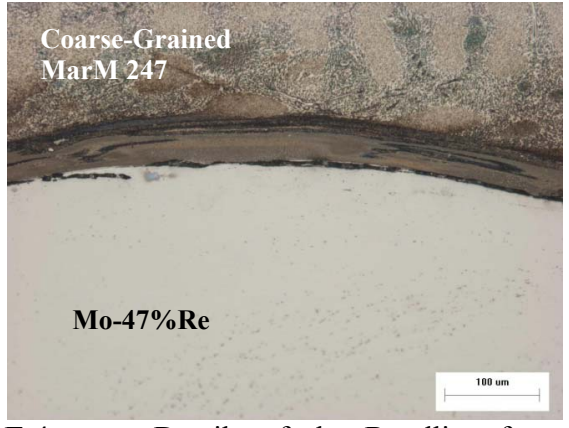

FIGURE 4. Details of the Bondline from a Mo47\%Re to Coarse-Grained MarM 247 Weld made at BestPractice Conditions in this Study.

ESD welding was done on four material combinations. These included the two refractory alloys (Mo- $47 \%$ Re and T111) to the two Ni-based alloys (Hastelloy $X$ and MarM 247). Welds were made with a Hastelloy $X$ filler (electrode). For these welds, a scalloped joint preparation was used. The developed welding practice resulted in a peak current on the order of about $180 \mathrm{~A}$ and a pulse width of roughly $60 \mu \mathrm{s}$. Assembly of each tensile specimen took roughly 8 hours. An example of the surface from a finished Hastelloy X to Mo-47\%Re ESD weld is shown in Figure 5 .

A sample macrostructure (for the Mo-47\%Re to Hastelloy $X$ combination) is shown in Figure 6. The macrostructure shows that the material was largely deposited from one side, with minimal dilution of the base materials. Results were similar for the Hastelloy X deposit on all four substrates and details of the Hastelloy X deposit microstructure are shown in Figure 7. The deposit is largely characterized by faint outlines of the individual splats and intermittent porosity. The former suggests splat sizes on the order of 1- to 10- $\mu \mathrm{m}$ thick and 10-50 $\mu \mathrm{m}$ in 
diameter. Interestingly, the underlying morphology was not readily revealed through conventional etching. The porosity shown typically lies along splat boundaries and is associated with lack of fill. The porosity level here appears to be less than about 5\%. It was noted that the fill microstructure was largely independent of the individual substrates. It appeared that once an initial layer was deposited on the substrates, the actual interactions occurring were only between the individual splats and the layered material. The porosity level here appears to be less than about $5 \%$.

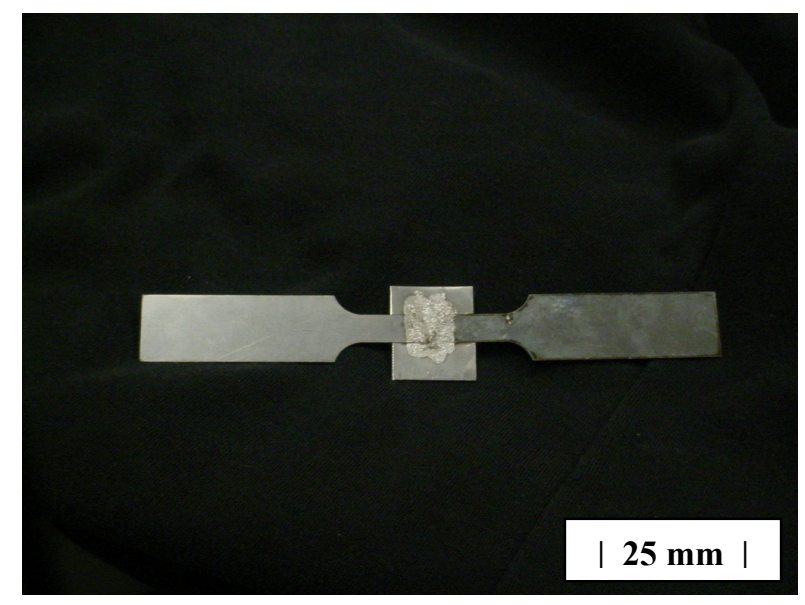

FIGURE 5. Resulting Hastelloy $X$ to Mo-47\%Re Specimen with Deposit after Joining with ESD Welding.

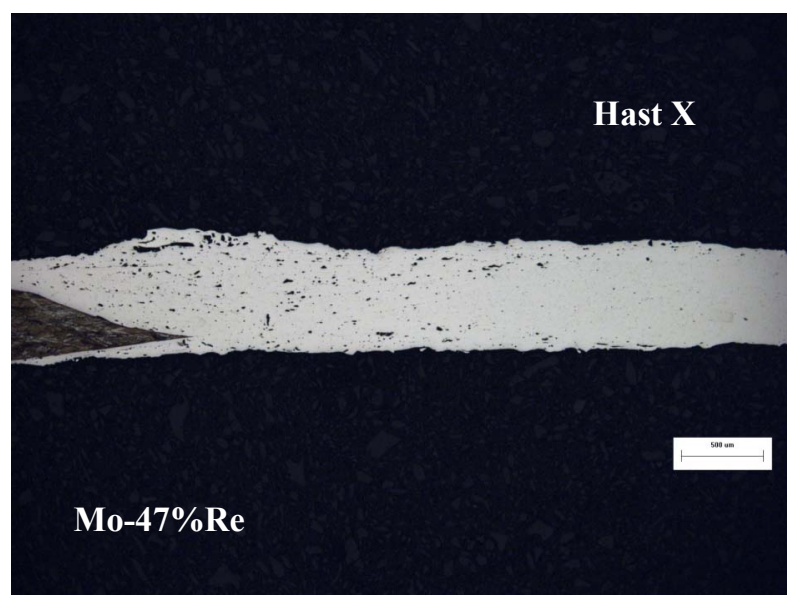

FIGURE 6. Macrosection of a Hastelloy $\mathrm{X}$ to Mo$47 \%$ Re ESD Weld.

Examples of the interfaces between the Hastelloy X fill and some of the substrates are presented in Figures 8-10. The Hastelloy X substrate is shown in Figure 8 and indicates that the scale of the deposit is comparable with the grain size of the base material. In addition, the transition from base metal to deposit microstructure appears to occur over about one or two layers of splats, consistent with the discussion above. The micrograph also shows some porosity in the deposited material with the level of porosity appearing to be consistent with the general fill material as described above. The interface against the MarM 247 substrate is shown in Figure 9. In this micrograph, the interfacial region again appears to be about one or two splat layers $(\sim 10-$ to $20-\mu \mathrm{m})$ thick. In this case, there does appear to be some mixing between the splat material and the MarM 247 substrate. This interfacial region appears to be of high integrity, adhered well to both the MarM 247 base material and Hastelloy X fill, and free of any cracks. Finally, Figure 10 presents the microstructure of the interface between the Mo- $47 \%$ Re substrate and the Hastelloy X fill. Of note here is the near non-existent dilution of the fill from the Mo- $47 \%$ Re substrate. It appears that the individual splats essentially wetted the Mo- $47 \%$ Re surface, and that buildup then continued on that deposited layer. Even at a micron level, the geometry of the Mo- $47 \%$ Re appears to be unchanged. Results for the deposits onto the T-111 material were similar.
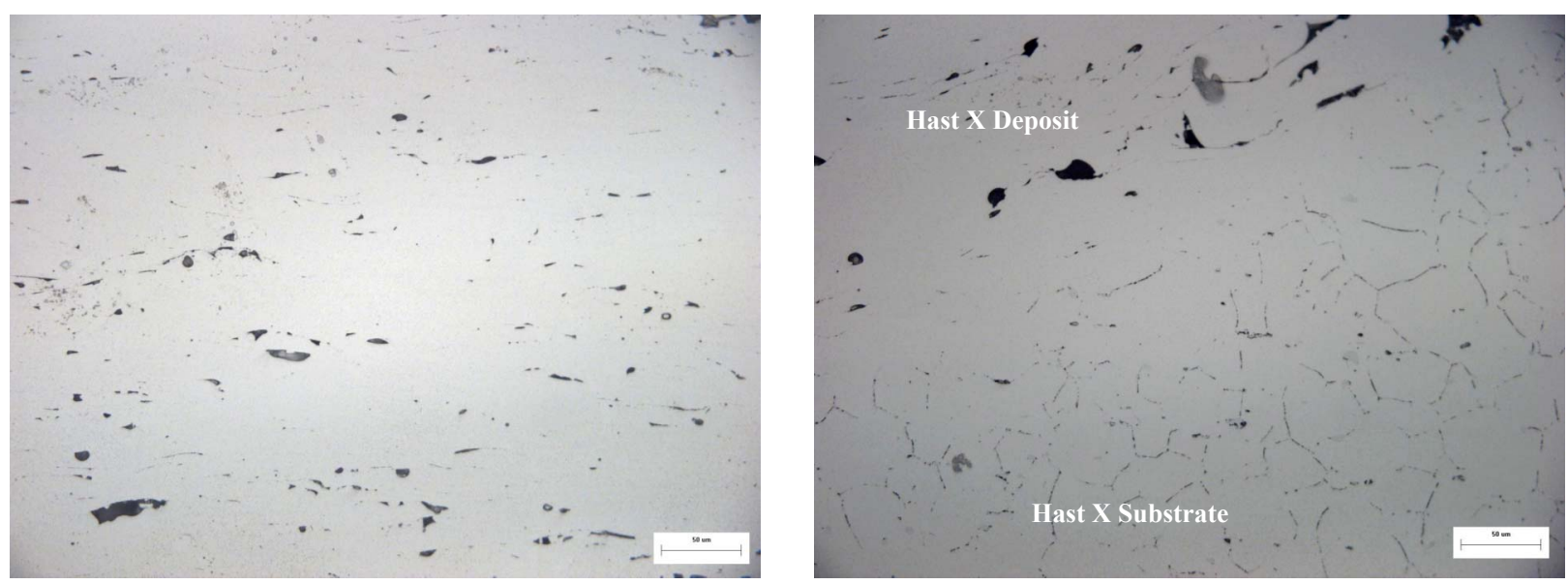
FIGURE 7. Microstructural Details of the Hastelloy X Deposit on a Hastelloy X to T-111 ESD Weld.

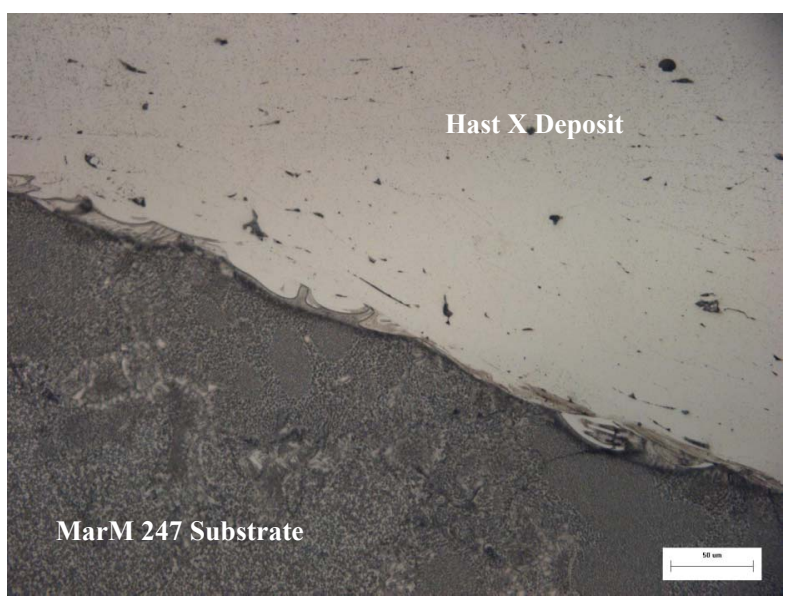

FIGURE 9. Details of the Interface Between a MarM 247 Substrate and the Hastelloy X Fill Material.
FIGURE 8. Details of the Interface Between a Hastelloy X Substrate and the Hastelloy X fill Material.

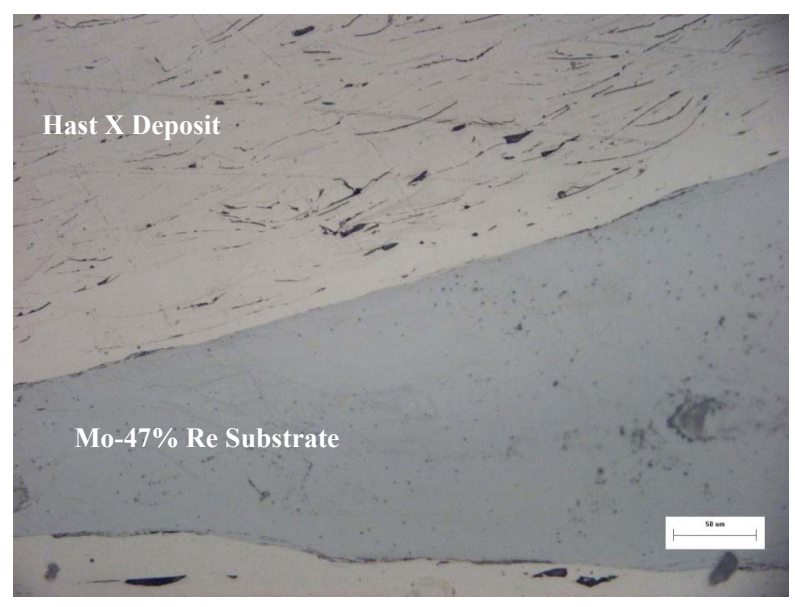

FIGURE 10. Details of the Interface Between a Mo$47 \%$ Re Substrate and the Hastelloy X Fill Material.

Due to limitations in material availability, trials were only conducted with the T-111 tube stock. Bonds were made with a peak current of over $1200 \mathrm{kA}$ and with a $38-\mu$ s pulse width with the resulting weld verified by petal testing, and there was substantial damage to the concentrator. A cross section of the joint is presented in Figure 11 and macrograph shows that the tube maintains intimate contact over a length of roughly $1 / 2$ in. It is also clear that the process resulted in substantial indentation of the target bar stock. Details of the bondline between the tube and bar stock are shown more clearly in Figure 12 where the wavy character of the bond line, typical of magnetic pulse welds is apparent (Shriban et al., 2000; Seregeeva, Chudakov, and Gordon, 1989; Stern and Aizenshtein, 2002). The micrograph also shows local deformation of the Hastelloy $\mathrm{X}$ bar stock and T-111 tube. In addition, small volumes of material which etch differently than either the Hastelloy X or T-111 base metals can be observed. Similar transition zones have been observed elsewhere for dissimilar magnetic pulse-welded joints (Seregeeva, Chudakov, and Gordon, 1989; Stern and Aizenshtein, 2002), and have been related to local resolidified volumes of molten material.

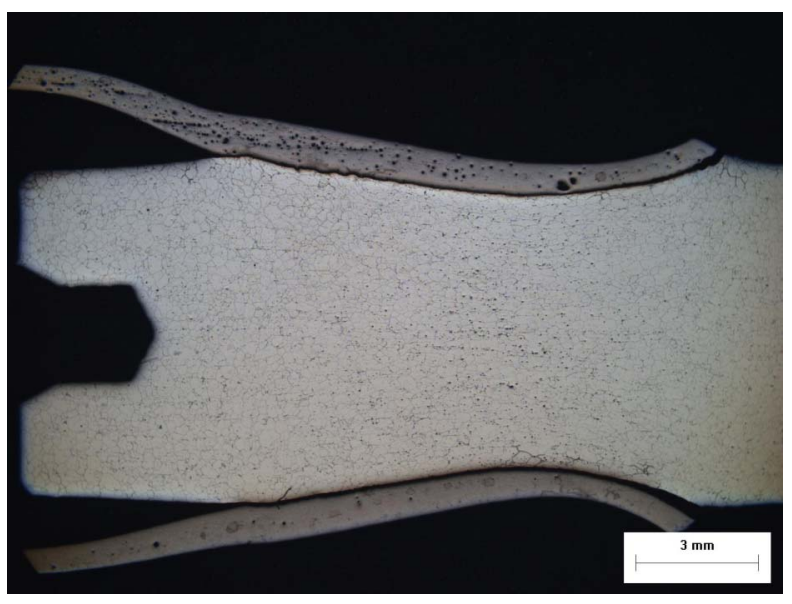

FIGURE 11. Cross Section of the Magnetic Pulse Weld made Between T-111 Tube and Hastelloy X Bar Stock.

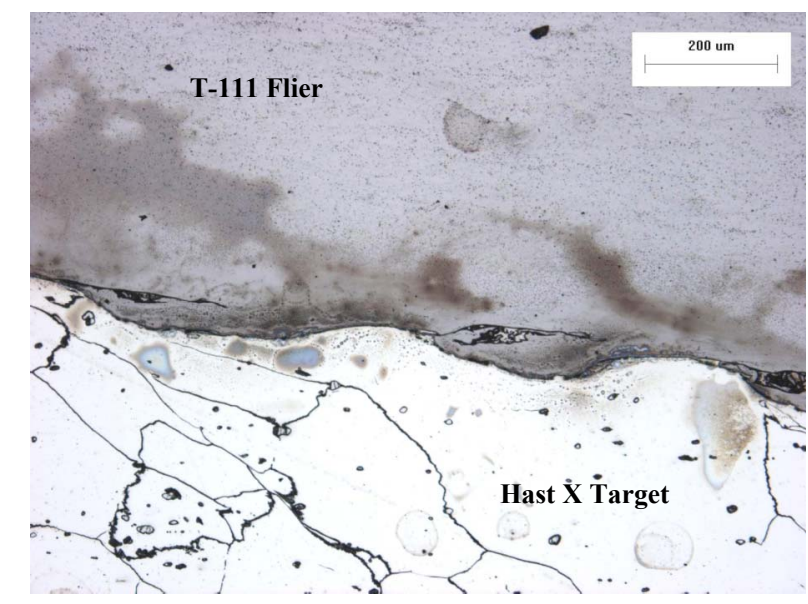

FIGURE 12. Details of the Interface from a Magnetic Pulse Weld made Between a T-111 Tube and Hastelloy X Bar Stock. 


\section{DISCUSSION}

Inertia welding of all six material combinations was accomplished using, essentially, the same processing conditions. These conditions nominally correlate to low inertias $\left(1.2-1.8 \mathrm{wk}^{2}\right)$, high surface velocities $(\sim 400 \mathrm{~m} / \mathrm{min})$ and low upset pressures $(83 \mathrm{MPa})$. These conditions also correlated well with previous corporate experience with refractory metal alloys. The processing for these dissimilar metal joints largely paralleled the requirements for Hastelloy X to itself. Certainly, for combinations using Hastelloy X, forging occurred predominantly that side of the joint. The MarM 247 materials exhibited similar behavior in that joining was not possible without at least surface deformation along the interface. It is of note that in order to achieve successful joints, at least some deformation was also required in the attached refractory metal. This deformation, however, was generally diffuse, and was seen potentially to be source of longitudinal cracking when combined with the higher temperature MarM 247 materials. Previous work (Zhang, 2005) has shown that solid-state joints result as a combination of contact surface disruption and residual oxide dissolution. Clearly, the disruption on the refractory metal surface was a necessary component to forming an effective weld. The results presented above also indicated considerable differences regarding inertia welding the refractory metals to the two variants (coarse- and fine-grained) MarM 247. Much of this related to the apparent higher forge temperatures of those materials. As mentioned above, the higher forge temperature resulted in reduced surface strains, inhibiting bonding.

ESD welds were found feasible on all material combinations when a Hastelloy $\mathrm{X}$ filler was used. The micro volumes of material transferred during the process were found to wet well against all substrates. In addition, the deposits were made with nearly no dilution from the substrates. As a result, within a few layers the process was essentially depositing Hastelloy X onto itself. The low dilution and effective wetting of the substrates are largely a factor of the implied cooling rates associated with this process. The process can be considered to deposit metal volumes with final thickness on the order of microns onto an essentially cold substrate in a period of microseconds. As a result, cooling rates are extremely rapid, and there is minimal time to conduct heat into the substrate (which would cause surface melting and dilution). In addition, the implied high cooling and solidification rates can suppress both complex solidification reactions as well as subsequent phase transformations, thereby in creating a high integrity joint. It was of note that even though the process was conducted in a low $(<1 \mathrm{ppm})$ oxygen environment, porosity could still be seen within the deposit. This porosity could be the result of two factors. First is simply the inability to fully wet the substrate at the implied cooling rates. The other is that some oxygen gettering may be occurring even at these low oxygen levels, forming oxides and facilitating locally poor wetting. However, as noted previously, the porosity level was only on the order of a few percent. With this technology (ESD), there is some question whether a higher density deposit can be achieved. Certainly, processing to prolong thermal cycles (longer pulse widths) in order to improve wetting characteristics will promote secondary metallurgical reactions, and are probably not advantageous. Work is needed to assess both the mechanical properties and leak performance with the current joining technology to determine if improvements are needed. The major drawback with the ESD joining technology is the deposition rate because ESD rates in the range of $\mu \mathrm{g} / \mathrm{s}$ require extended processing times (up to 10 's of hours) to create a joint. The slow processing speed, however, is partially responsible the metallurgical benefits seen in this study. Efforts to improve deposition rates invariably will raise either the scale of metal transfer or the temperature of the substrate, or both. As a result, efforts to improve the productivity of the technology must be tempered by the metallurgical considerations of both the substrate and fill materials.

Preliminary evidence from this study suggested that magnetic pulse joints could be made between the Mo- $47 \% \mathrm{Re}$ and the Hastelloy X materials provided that sufficient energies could be obtained. These high energies, unfortunately, caused substantial damage to the concentrator. It must be pointed out, however, that both the high power requirements as well as system damage are largely related to the geometry of the configuration investigated. Previous experience (Zhang, 2005) has shown that there are requirements between flier diameter, tube wall thickness, and material yield strength if MPW is to be achieved without damage to the concentrator. This experience suggests that for $0.9-\mathrm{mm}$ wall thickness refractory motor tube, diameters on the order of $50 \mathrm{~mm}$ are necessary to prevent concentrator damage. It is of interest that the MPW microstructures seen here are strikingly similar to those of the ESD trials. This is a direct result of the thermal excursions associated with the two processes. As suggested above, the discharge time for ESD is roughly $60 \mu \mathrm{s}$, and the residual splat size is roughly 5- to $10-\mu \mathrm{m}$ thick. The discharge time from the MPW system is roughly $40 \mu$ s and leaves a residual melt layer roughly 5- to 10$\mu \mathrm{m}$ thick. The result is similar cooling rates of the interfacial material, with similar resulting microstructures. Finally, it was seen that MPW was not well suited for joining onto a MarM 247 target. Apparently, the fracture 
toughness of the MarM 247 was insufficient to withstand the necessary impact forces necessary to form the liquid layers necessary for bonding.

\section{CONCLUSIONS}

In this program, candidate joining technologies for attaching some representative refractory alloys to Ni-based superalloys have been investigated. The refractory metals have included Mo- $47 \% \mathrm{Re}, \mathrm{T}-111$, and Ta- $10 \% \mathrm{~W}$. Nibased superalloys evaluated included wrought Hastelloy X and cast MarM 247 in the coarse- and fine-grained conditions. For these material combinations, three welding processes were investigated. These included inertia welding, ESD welding, and MPW. Inertia welding trials suggested that all of the candidate refractory metal could be bonded to Hastelloy X, although varying degrees of success were obtained with the MarM 247 alloys. Processing was similar to that seen for welding the Hastelloy X to itself. ESD welding with a Hastelloy X filler was also found readily feasible with minimal dilution of or reaction with the respective substrates. However, excessively long weld times were required to create the ESD joints. Finally, MPW of the T-111 material to the Hastelloy X was found feasible, but the power requirement and geometries of the flyer and target used in this study resulted in excessive damage to the concentrator. Similarities were found between the microstructures of the ESD and MP welds. This was related to the discharge pulse widths associated with these processes. These results offer potential for joining these materials in a range of designs. Work is under way to further characterize these welds. Additional work will be needed to fully optimize these processes.

\section{ACKNOWLEDGMENTS}

The work described in this paper was performed for the NASA Exploration Systems Mission Directorate and the Prometheus Nuclear Systems and Technology Program. Any opinions, findings, and conclusions or recommendations expressed in this presentation are those of the authors and do not necessarily reflect the views of the National Aeronautics and Space Administration.

\section{REFERENCES}

Efimenko, A. A., Belenkii, E. I., Kalenichenko, A. V., and Korol, Y.A.D., "Examination of the Interface of Copper/Aluminium Pipes Welded by Magnetic-Pulse Welding," Weld. Prod. 32(10):30-31 (1985).

Galinov, I. V. and Luban, R. B., "Mass Transfer Trends during Electrospark Alloying," Surface Coatings and Technology, 79:9-18 (1996).

Hokari, H., Sato, T., Kawauchi, K., and Muto, A., "Magnetic Impulse Welding of Aluminium Tube and Copper Tube with Various Core Materials," Welding International, 12(8):619-626 (1998).

Johnson, R. N. and Sheldon, G. L., "Advances in the Electrospark Deposition Coating Process," Journal of Vacuum Science \& Technology A, 4(6):2740-2746 (1986).

Johnson, R. N., "Principals and Applications of Electro-Spark Deposition," Surface Modification Technologies, TMS, Warrendale, PA, 1988.

Khrenov, K. K. and Chudakov, V. A., “Magnetic-Pulse Welding,” Avtomat Svarka, (2):74-75 (1968).

Li, Z., Gao, W., Kwok, P., Li, S., and He, Y., High Temperature Materials and Processes, 19(6):443-458 (2000).

Markashova, L. I., Sergeeva, Y. A., Statsenko, V. V., and Chudakov, V. A., "Special Features of the Mechanism of Structure Formation in Magnetic Pulsed Welding," Paton Welding Journal, 3(3):187-191 (1991).

Masumoto, I., Tamaki, K., and Kojima, M., "Study on Electromagnetic Welding - Report 1: Electromagnetic Welding of Aluminium Tube to Aluminium or Dissimilar Metal Cores," Transactions of the Japan Welding Society, 16(2):110-116 (1985).

MTI Manual for Inertia Parameter Assistance. Manufacturing Technology Incorporated, Mishawaka, IN.

Powers, H. G., "Bonding of Aluminium by the Capacitor Discharge Magnetic Forming Process," Welding Journal, 46(6):507-510 (1967).

Seregeeva, Y.U.A., Chudakov, V. A., Gordon, G. N., "Examination of the Transition Zone in Magnetic Pulse Welded Joints Between Aluminium and Copper,” Paton Weld. J., 1(12):874-877 (1989).

Sheldon, G. L. and Johnson, R. N., "Electro-Spark Deposition - A Technique for Producing Wear Resistant Coatings," Wear of Materials 1985, ASME, New York, NY, 1985. 
Shriban, V., Livshitz, Y., Gafri, O., and Kimchi, M., "The MPW Process," Third International TWI/EWI Workshop on Joining of Aerospace Materials, 2000.

Stern, A. and Aizenshtein, M., "Bonding Zone Formation in Magnetic Pulse Welds," Science and Technology of Welding and Joining, 7(5):339-342 (2002).

Wand, P.-Z., Pan, G.-S., Zhou, Y., Qu, J.-X., and Shao, H.-S., "Accelerated Electrospark Deposition and the Wear Behavior of Coatings," Journal of Materials Engineering and Performance, 6(6):780-784 (1997).

Welding Handbook, $8^{\text {th }}$ Ed, Volume 2: Welding Processes: Chapter 23, Friction Welding, edited by R. L. O'Brien, American Welding Society, Miami, FL, 1991, pp. 739-764.

Zhang, P., Private Communication, Edison Welding Institute, 2005. 